\title{
Proliferation and Differentiation of Rat Neuroepithelial Precursor Cells in vivo
}

\author{
K. Frederiksen and R. D. G. McKay \\ Departments of Biology and Brain Science, Whitaker College, Massachusetts Institute of Technology, Cambridge, \\ Massachusetts 02139
}

\begin{abstract}
Important features of adult neuronal number, location, and type are a consequence of early embryonic events that occur before neurons have differentiated. We have measured cell number during embryogenesis of the rat CNS. Markers that are expressed in the proliferating neuronal precursor are required to study the mechanisms controlling their proliferation and differentiation. By applying immunohistochemistry, fluorescence-activated cell sorting, and ${ }^{3} \mathrm{H}$-thymidine autoradiography to dissociated rat CNS cells, we show that the monoclonal antibody Rat $\mathbf{4 0 1}$ recognizes a cell population with proliferative, temporal, and quantitative features expected of neuronal precursors.
\end{abstract}

Transplantation experiments show that differentiated features of adult CNS neurons are determined before neuronal differentiation between the late gastrula and the early neurala stages of embryonic development (Mangold, 1929; Jacobson, 1978; Chung and Cooke, 1975). In the neurala, the columnar cells of the neurectoderm are morphologically homogeneous. The first major change in cell morphology appears on neuronal differentiation. At this time, the 2 major morphological classes of embryonic neural cell are seen, radial cells stretching across the epithelium and postmitotic neurons which go through their last mitosis at the ventricular surface of the epithelium and then migrate towards the opposite, pial, surface, where they extend axons (Fig. 1).

Functionally different classes of neurons are found in specific locations in the adult brain. This characteristic structure is a consequence of 2 features of neuronal development. First, particular types of neurons are generated together in a precise temporal and spatial sequence of differentiation. Second, the migration of postmitotic neurons to the periphery is controlled so that neurons born at different times migrate to particular locations relative to other neurons (Sauer and Walker, 1959; Sidman et al., 1959; Angevine, 1970; Rakic, 1972, 1974). It is clear from these facts that understanding both the numerical and functional complexity neurons in the adult brain will require detailed knowledge of the mechanisms controlling number and fate of neuronal precursor cells.

The number of neurons in the adult brain is derived from 2

Received June 24, 1986; revised Aug. 6, 1987; accepted Sept. 10, 1987.

This work was supported by grants from the National Institutes of Health, the Whitaker Health Science Fund, and the Rita Allen Foundation. It is also a pleasure to acknowledge the generous gifts of antibodies used in this study from S. Blose M. Matthews, R. Liem, W. Stallcup, and R. Hynes.

Correspondence should be addressed to Ron McKay, E25-435, Whitaker College, M.I.T., Cambridge, MA 02139.

Copyright (C) 1988 Society for Neuroscience $0270-6474 / 88 / 041144-08 \$ 02.00 / 0$ independent processes, an early proliferative phase operating on neural precursor cells and a later phase of selective death of differentiated neurons (Glucksmann, 1951; Prestige, 1970; Cowan, 1979). As neurons do not divide, a proliferating precursor cell must exist. Biochemical markers for differentiated neurons are not generally expressed in proliferating cells in the CNS. It follows that neuronal precursor cells must be biochemically distinct from neurons. It is this neuroepithelial precursor cell that responds to spatial and temporal cues in the neuroepithelium to generate distinct neuronal types in precise numbers and at specific locations and times.

In the experiments reported here, we measured the increased CNS cell number during embryonic development, characterized the proliferating cells at different embryonic ages, and identified an antigenic marker expressed in proliferating cells during neurogenesis.

\section{Materials and Methods}

Materials. Timed pregnant Sprague-Dawley rats were obtained from Taconic (NY). The Rat 401 mouse monoclonal antibody [IgG(1),K] was raised by injecting Balb $\mathrm{C}$ mice with fixed embryonic neural tube of the E15 rat (Hockfield and McKay, 1985). The E15 rat embryo was chosen because neurogenesis is underway at this time. Anti-vimentin antisera were obtained from R. Hynes (MIT), R. Liem (NYU), and monoclonal antivimentin from $\mathrm{S}$. Blose (Protein Databses Inc.). Anti-cyclin antiserum was a gift of M. Matthews (CSH Lab.). Monoclonal antibody D1.1 was a gift of W. Stallcup (La Jolla CRF). Conjugated second antibodies were supplied by Cappell, Inc. (PA).

Cell dissociation. The neural tube was dissected from embryos, which were staged according to Christie (1965). For embryos from E9-E11, the neural tube and surrounding mesenchyme were incubated in $0.1 \%$ Trypsin (Sigma, type II), PBS $\left(\mathrm{Ca}^{2+}, \mathrm{Mg}^{2+}\right.$ free) for $1 \mathrm{hr}$ at $25^{\circ} \mathrm{C}$. The reaction was terminated by washing in $0.1 \%$ Trypsin inhibitor in PBS. The tissue adhering to the neural tube was removed with electrolytically sharpened tungsten wires. From E12 onwards, proteolytic digestion was omitted, and the neural tube was dissected free of the leptomeninges and incubated in hypotonic PBS for $2 \mathrm{hr}$ at $22^{\circ} \mathrm{C}$. Regardless of age of embryo, the neural tube was separated into several regions: cerebrum (note that the cerebral region also contains the hippocampus), midbrain, brain stem, cerebellum, and spinal cord. The cells were dissociated using a $1 \mathrm{ml}$ Gilson pipetteman with a disposable plastic tip. All these steps were carried out in siliconized plastic ware. After trituration, aliquots of cell suspension were placed directly onto a coverslip gyroscopically mounted in a centrifuge tube (unpublished design). This gyroscope allowed the cells to be centrifuged onto the coverslip (2000 rpm, $10 \mathrm{~mm}$ ) without coming in contact with the side walls of centrifuge tubes. Once attached to the glass, the supernatant was air-dricd and the cells fixed in $4 \%$ paraformaldehyde. As the primary goal of these experiments was measuring cell number, the procedures are not optimized for cell viability.

Cell staining. Cell counts were performed by staining nuclei with Hoechst $33258\left(1 \mathrm{ng} / \mathrm{ml}\right.$ in PBS, $\left.15 \mathrm{~min}, 25^{\circ} \mathrm{C}\right)$. For immunohistochemistry coverslips were incubated sequentially for $2 \mathrm{hr}$ with the first antibody diluted in DMEM $+5 \%$ fetal calf serum and in rhodamine- 
or fluorescein-conjugated second antibody. Coverslips were washed after each antibody incubation in DMEM $+5 \%$ FCS. Antibodies that did not recognize cells in the neural tube were used as controls. For flow cytofluorimetry, cell suspensions were fixed and stained in solution.

Flow cytometry. Propidium iodide quantitatively intercalates into double-stranded DNA, where it fluoresces a brilliant orange. A $1 \mathrm{ng} /$ $\mathrm{ml}$ solution of propidium iodide in PBS was used to stain fixed cell suspensions, which were passed through an Orthocytofluorograph system 50 sorter (equipped with an Ar laser, $500 \mathrm{mV}, 488 \mathrm{~nm}$ ) interfaced with an Ortho 2150 computer. The cell cycle constant method was used to calculate the distribution of cells in G1, S, and G2 phases of the cell cycle (Gray and Dean, 1980).

Cell numbers. 1. The number of nuclei in several $50 \mu \mathrm{l}$ aliquots of cell suspension were counted by $\mathrm{H} 33258$ fluorescence. The average was then used to give the number of cells $/ 50 \mu$ of cell suspension. The total number of cells was derived by multiplying the number of cells in 50 $\mu \mathrm{l}$ by the known volume of cell suspension for a particular brain region. These manipulations wcre repeated for between 3 and 7 embryos at a given developmental age and the SDs calculated. The proportion of 401 -positive cells at different developmental times was calculated by counting more than 100 cells at different developmental times. The FACS was also used to determine the proportion of Rat 401 -stained cells. Quantitative FACS analysis showed that Rat 401-positive and -negative populations could be clearly separated. The proportions of stained cells obtained by flow cytometry and visual inspection were in close agreement.

2. An independent measure of the number of cells in the embryonic CNS was obtained by measuring the total amount of DNA in the E15 and $\mathrm{E} 19$ nervous system. The dissected neural tube was homogenized, without cell dissociation, and the amount of DNA measured using Hoechst 33258 and the method of Labarca and Paigen (1980). To convert this value into the number of cells 2 further facts must be known: the diploid value of DNA in the rat nucleus and the proportion of cells in the $S$ and $G 2$ phases of the cell cycle at the appropriate developmental stage. The diploid value of DNA in rat cells we have used is $6.4 \times 10^{-12}$ gm (Santen and Agranoff, 1963). The proportion of cells in different phases of the cell cycle was measured by staining dissociated single-cell suspensions of embryonic CNS cells with propidium iodide and analyzing the DNA content by flow cytometry. The percentage of cells in G1, S and G2 at E15 was $81.2 \pm 4.3,14.9 \pm 3.0$, and $4.8 \pm 0.6(n=$ 3 ) and at E19 was $89.4,6.9$, and 4.8 . The major potential source of error in this data is the possibility that $2 \mathrm{Gl}$ cells pass through the sorter in the same drop. These doublets, which would be counted as a cell in $\mathrm{G} 2$, were excluded by applying standard programs that recognize the area emitting the signal. To confirm that these programs were, in fact, excluding doublets, the cells in the G2 category were sorted and analyzed microscopically. No doublets were seen. As the propidium iodide measurements show that cells proceed linearly through $\mathrm{S}$ phase, the number of cells in the E15 neural tube was calculated by simple proportion.

\section{Results}

\section{Cell numbers in the embryonic CNS}

The CNS from E10-E1 3 rat embryos was dissected after trypsin treatment. In older embryos, E 14 and on, the CNS was separated from other tissue by mechanical dissection only. $\Lambda t$ all stages the neuroepithelium was dissected from the leptomeninges and then dissociated by trituration. Aliquots of the cell suspension were placed on a coverslip, and the cells attached to the glass by centrifugation. After air-drying, the cells were fixed in $4 \%$ paraformaldehyde and stained with the DNA intercalating dye Hoechst 33258. This fluorescent dye stains nuclei a brilliant blue and allows the number of nuclei in the aliquot of spundown cells to be counted readily (Fig. 2). The total number of cells in the CNS and the number of cells in different regions of the CNS are shown in Figures 3 and 4.

An independent measure of the numbers of cells in the embryonic nervous system derived from Hoechst spectrofluorimetric values of the total DNA content using the method of Labarca and Paigen (1980). The cell numbers obtained with this method (Fig. 3, triangles) are in close agreement with the num-
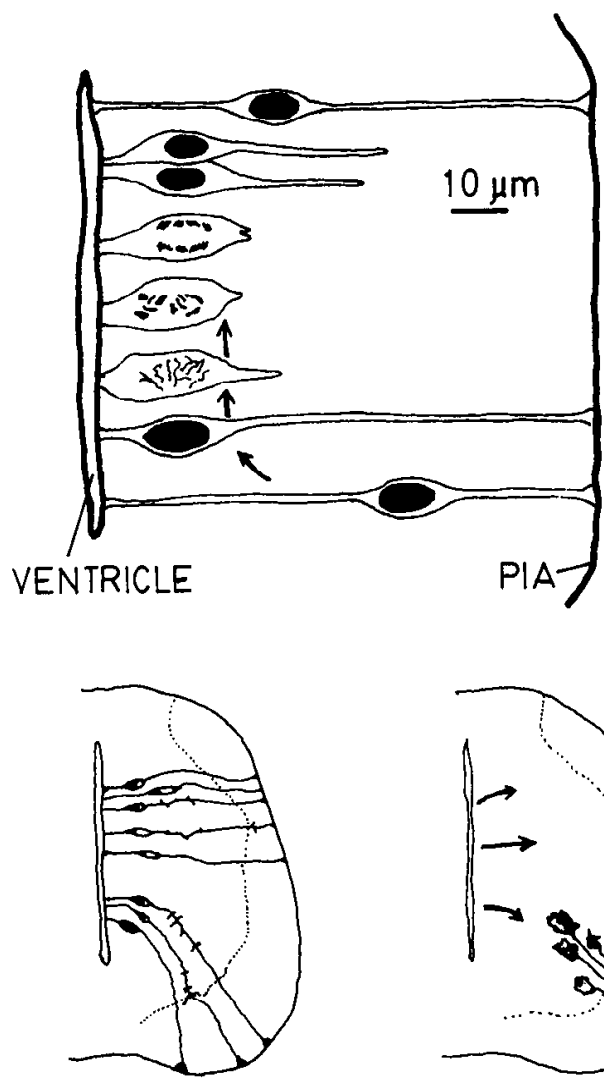

RADIAL GLIA

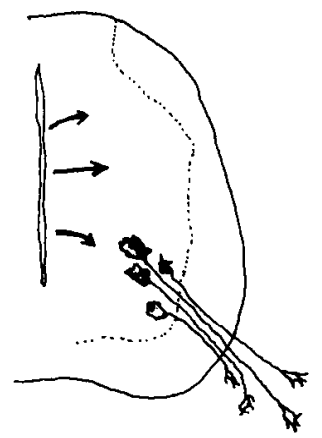

NEURONS

Figure 1. Cell types in the neuroepithelium. Top, Like all epithelia, the cells of the early neural tube stretch from one surface to the other. Mitosis takes place at the venticular surface, and as dividing cells go through the cell cycle, nuclei migrate to a more peripheral location and then back to the ventricle. Bottom, At the time of neurogenesis both neurons and cells with a radial morphology differentiate. Neurons are derived from dividing cells that go through mitosis in a specialized subventricular or germinal zone $(G Z)$. After neurons become postmitotic, the cell bodies take up a peripheral location; there they extend axons in specific locations, forming the characteristic pattern of gray and white matter found in different brain regions.

bers obtained by counting the nuclei in aliquots of dissociated cells.

The total cell number in the nervous system increases from E10 to E20, and then once again after birth the numbers increase sharply. Many studies show that neurons are generated in the embryo and that the majority of glial cells arise postnatally. Cell numbers increase 1,000-fold from $10^{5}$ on $\mathrm{E} 10$ to $10^{8}$ on $\mathrm{E} 21$. If all the cells in the E10 neural tube were to divide equally, this increase in cell number requires 10 divisions. In the rat spinal cord, the ventral motor neurons go through their last mitosis on E1 1 and differentiate on E12. The dorsal neurons, which are the last to differentiate, go through their last mitosis on E15 (Nornes and Das, 1974). Our data (Fig. 4) show that the total number of cells in the spinal cord reaches a maximum on E15 and then remains constant until birth. In the cerebrum neurons differentiate from E16 to E21 (Berry et al., 1964; Berry and Rogers, 1965). Our data show that there is a 20 -fold increase in cell number during neurogenesis in the cerebrum and in this brain region, like the spinal cord, there is a period after neurogenesis when cell numbers remain relatively stable until the 


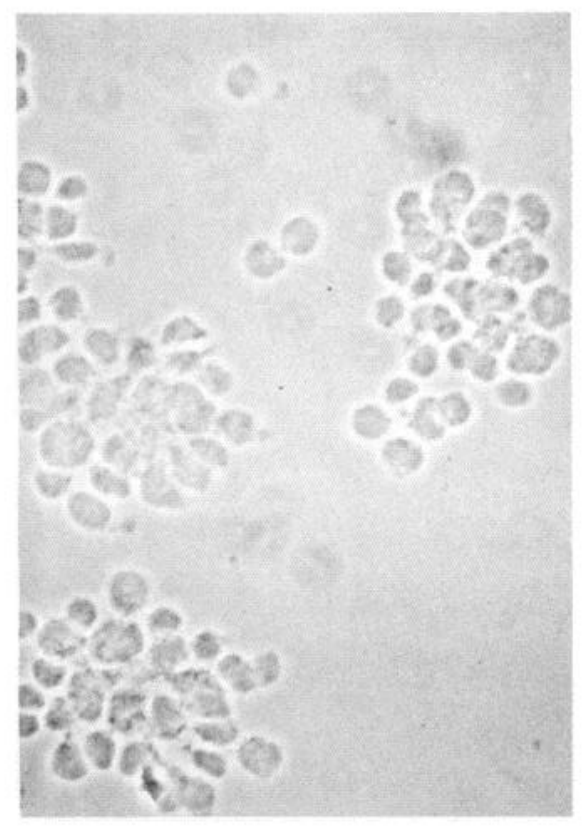

A
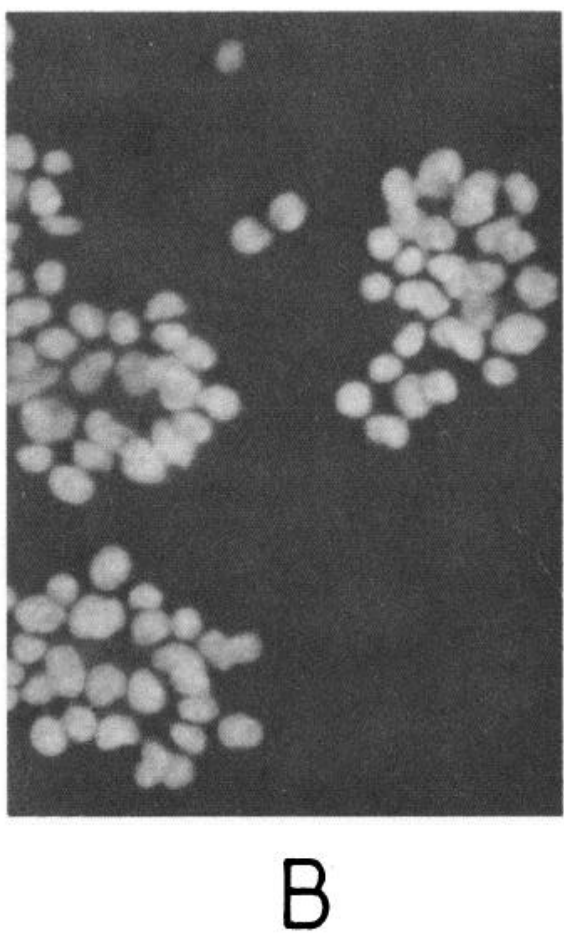
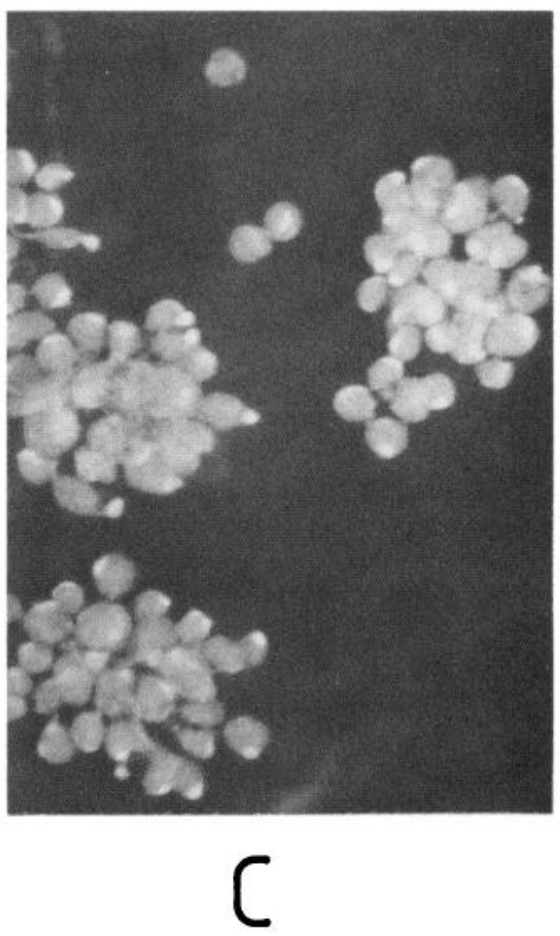

Figure 2. Double labeling of dissociated CNS cells. Aliquots of dissociated neural cells were attached to coverslips and photographed in phase contrast $(A)$ and after double labeling with Hoechst $33258(B)$ and Rat 401 staining $(C)$. The cells shown were obtained from the cerebrum of an E12 embryo.

second postnatal week, when the number of cells again increases coincident with the generation of large numbers of glial cells.

\section{Immunohistochemical identification of neuronal precursors}

Several antigens have been identified in the neuroepithelium at the time of neuronal differentiation. In particular, antisera against

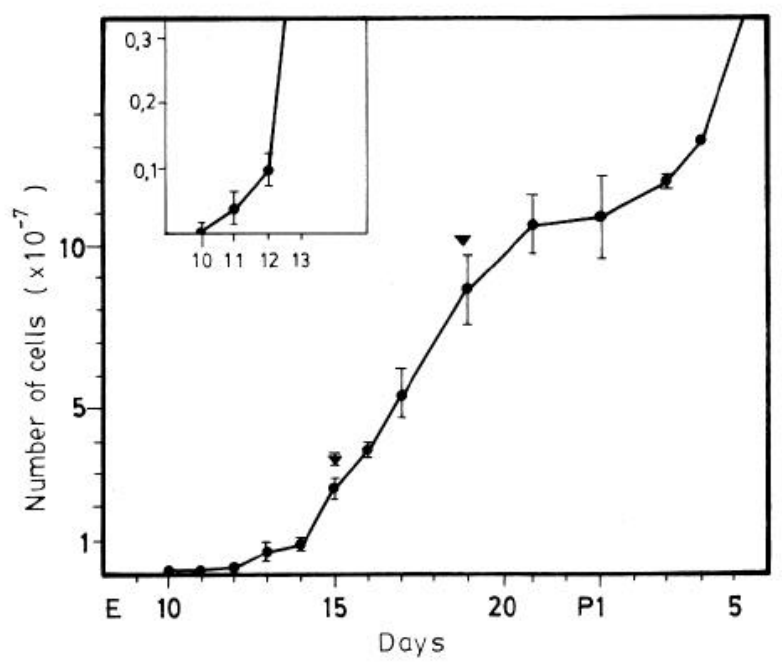

Figure 3. Total cell numbers in the embryonic rat CNS. Dissociated CNS cell suspensions were stained with Hoechst 33258 and the cell number in aliquots calculated $(\bullet)$. The cell number estimated from the DNA content of the CNS is also shown $(\boldsymbol{\nabla})$. Timed pregnant animals were used in these studies, and the developmental stage of each embryo was assessed by the criteria developed by Christie (1965). For each developmental stage, several animals were used and the SD on measurements of several animals (3-7) is shown. the intermediate filament protein vimentin (Tapscott et al., 1981; Bignami et al., 1982; Fedoroff, 1985) and 3 monoclonal antibodies-A2B5 (Raff et al., 1985), D1.1 (Levine et al., 1984), and Rat 401 (Hockfield and McKay, 1985) - have been localized in the proliferative zone of the neuroepithelium.

The spatial distribution of antigens in the E15 spinal cord was used to give an initial indication of antigens expressed in neuronal stem cells (Fig. 5). At this stage in embryonic development, autoradiographic studies have shown that neurons in the ventral half of the spinal cord have already been generated and the proliferative ventricular zone reduced in size (Nornes and Das, 1974). This can be clearly seen in Figure $5 E$, where a cross section of the E15 spinal cord has been stained with anti-

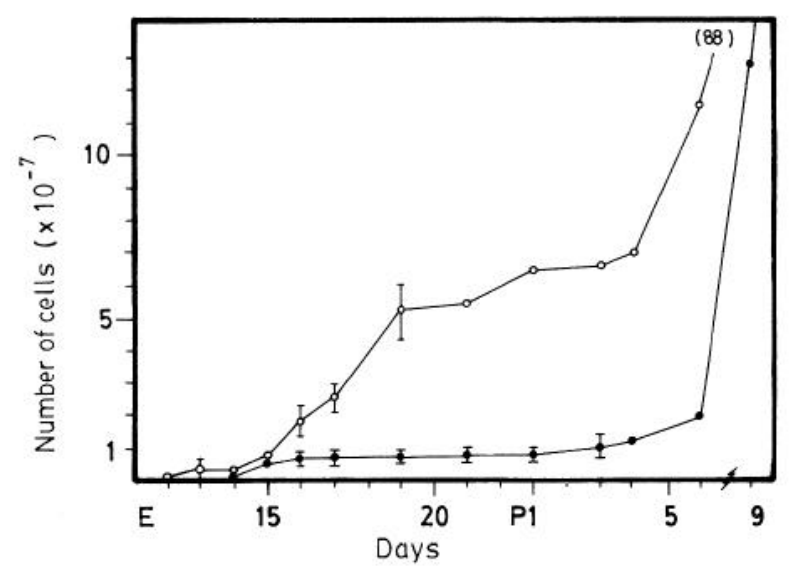

Figure 4. Cell number in the cerebrum and spinal cord. Cell numbers were calculated from dissociated cell suspensions as in Figure 3. The numbers of cells in the cerebrum $(\mathrm{O})$ and the spinal cord $(\bullet)$ are shown. 

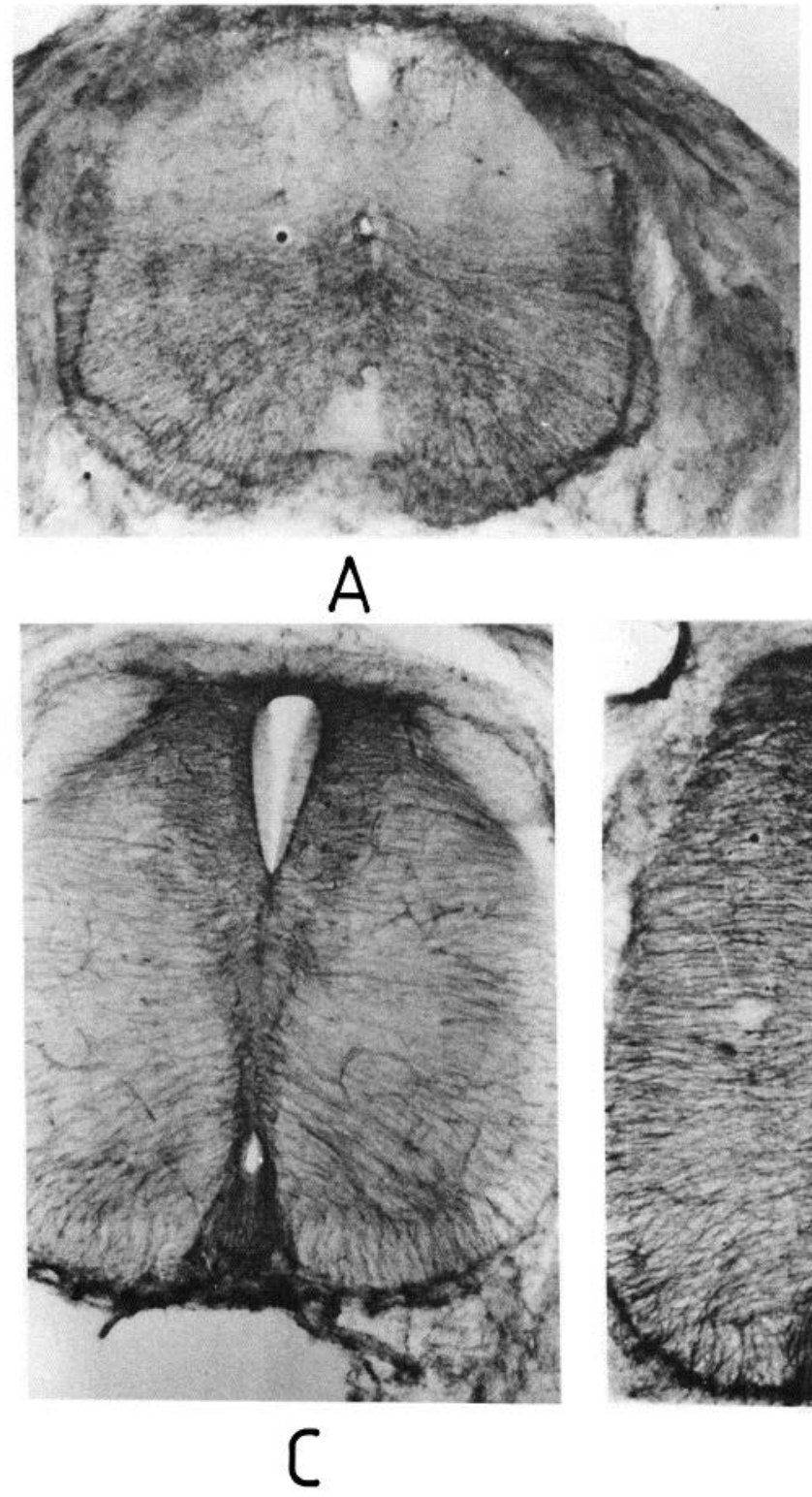
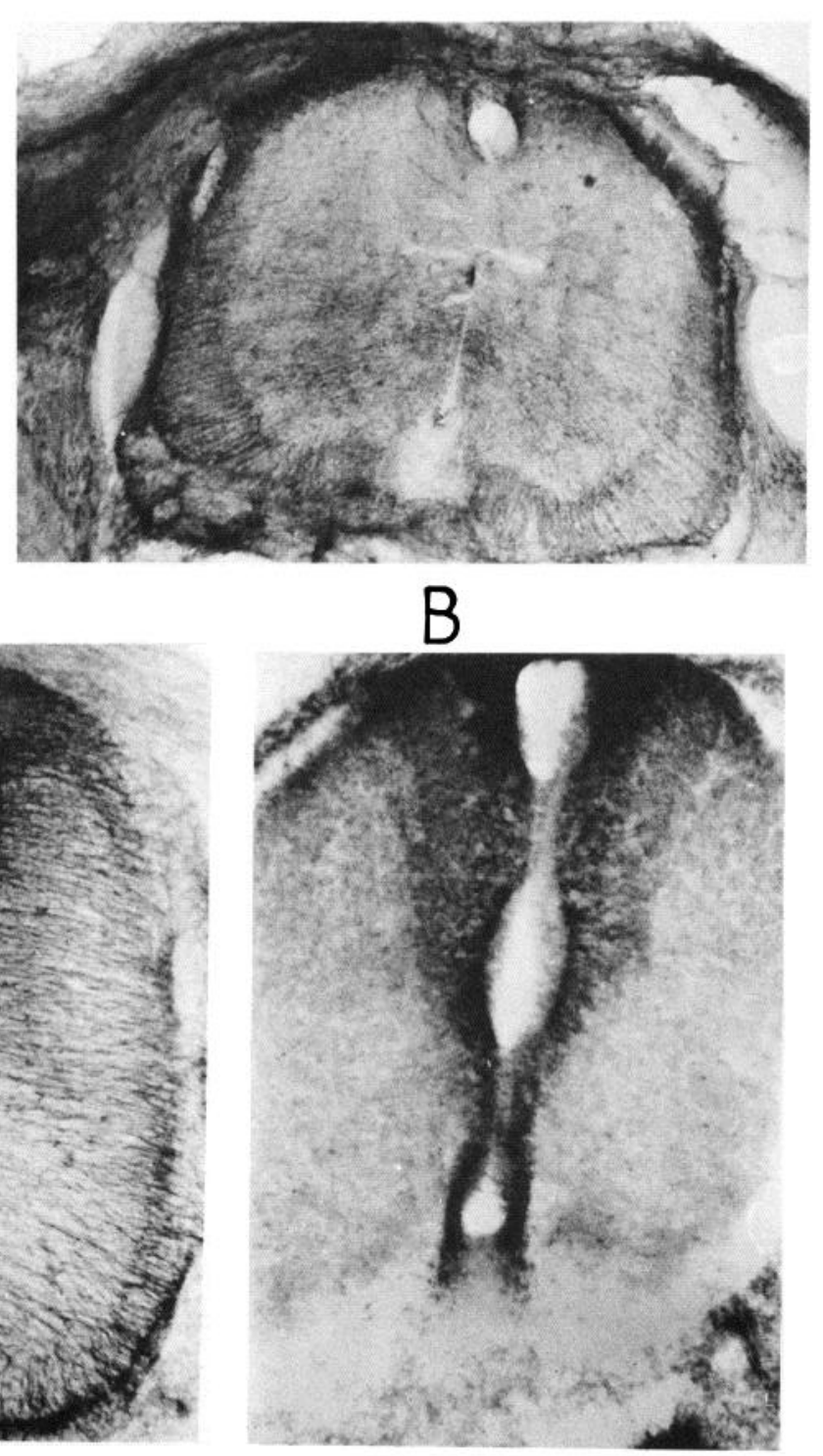

E

Figure 5. Immunohistochemistry on the E15 spinal cord. Vibratome sections of E15 rat embryo spinal cord were reacted with mouse monoclonal antibodies A2B5 $(A)$, D1.1 $(B)$, anti-vimentin $(C)$, and Rat $401(D)$. All 4 antibodies bind to radial processes in the ventral cord. A2B5 and D1.1 do not react strongly with the dorsal cord. In contrast, the anti-vimentin antibody and Rat 401 bind to cells in the dorsal cord. At this time, cells in the dorsal cord are still dividing to give neurons. The distribution of cells in the S phase of the cell cycle is shown in $E$. These cells were stained with a human antiserum against the protein cyclin, which is expressed at high levels in rat cells replicating their DNA.

cyclin. Cyclin is a protein present in larger amounts during the $\mathrm{S}$ phase of the cell cycle (Bravo and Bravo-McDonald, 1985), making detection of actively proliferating cells possible. The large number of proliferating cells in the dorsal ventricular zone $\left(\mathrm{VZ}_{\mathrm{d}}\right)$ contrasts with fewer cells and restricted width of the ventral ventricular zone $\left(\mathrm{VZ}_{\mathrm{v}}\right)$.

The antigens recognized by $\mathrm{A} 2 \mathrm{~B} 5$ and $\mathrm{D} 1.1$ (Fig. 5, $A, B$ ) are predominantly found on cells in ventral regions of the spinal cord. The stained cells are both in the ventricular zone and in the peripheral regions, where radial staining is seen. Cells expressing vimentin and Rat 401 antigen are found in both dorsal and ventral regions of the spinal cord (Fig. 5, C,D). The localization of these antigens suggests that Rat 401 antigen and vimentin are expressed in the cells of the neuroepithelium before neurons differentiate. In contrast, the antigens recognized by
A2B5 and D1.1 are not expressed at high levels in the dorsal spinal cord during the major period of neurogenesis.

\section{Proportion of Rat 401-positive cells in neural development}

Although the immunohistochemical analysis of the cell populations expressing A2B5, D1.1, Rat 401 antigens, and vimentin is not complete, the data in Figure 5 suggest that Rat 401 antigen and vimentin are expressed at high levels in the dorsal proliferative zone of the neuroepithelium during neurogenesis. We have measured the number of Rat 401 cells at different developmental times. Figure $2 C$ shows that Rat 401 binds to dissociated CNS cells. On E10 the antigen is present in some cells and has a restricted localization. The point on the cell where the antigen is first seen in dissociated cells most probably corresponds to the pial end foot, as this is where the antigen is first 


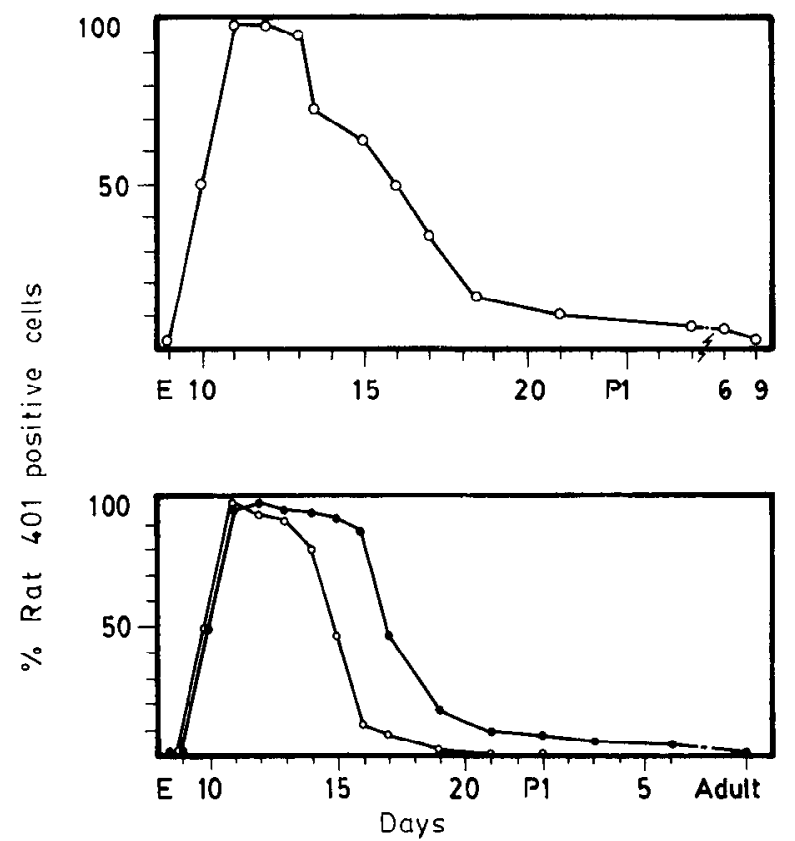

Figure 6. Proportion of Rat 401 -positive cells. A, Proportion of cells in the total CNS stained with Rat 401 on different embryonic days. $B$, Proportion of Rat 401-positive cells in the cerebrum (@) and spinal cord (O).

seen in tissue sections (Hockfield and McKay, 1985). The proportion of 401-positive cells increases rapidly to a maximum on days E11 and 12, when $98 \%$ of the cells are stained. After E1 2 the proportion of cells stained with Rat 401 declines (Fig. 6). The disappearance of the antigen in dissociated cells correlates well with previous in vivo studies (Hockfield and McKay, 1985).

Figure $6 \mathrm{~A}$ shows that Rat 401-positive cells are first seen on E10, and by E11 more than $98 \%$ of the cells in the brain express this marker. After this peak in expression, the number of cells expressing Rat 401 antigen declines. In the spinal cord and cerebrum the cells first express Rat 401 on E10, and by E11 more than $95 \%$ of the cells are stained (Fig. $6 B$ ). In the spinal cord the proportion of stained cells falls sharply between E1 1 and E16 which is the known period of neurogenesis (Nornes and Das, 1974). In the cerebrum (Fig. 6B) the proportion of Rat 401-positive cells falls sharply between E16 and E21 and again correlates with neurogenesis. Berry et al. (1964) showed that layer VI neurons become postmitotic on E16 and layer II neurons on E21.

These results show that in the spinal cord and cerebrum monoclonal antibody Rat 401 identifies almost all cells in the neuroepithelium prior to neurogenesis and that the proportion of Rat 401-positive cells coincides with neurogenesis. The few cells that are not Rat 401 positive at the start of neurogenesis may be endothelial cells, as this cell type is first seen in the nervous system at this time (Hockfield and McKay, 1985).

\section{Rat 401-positive cells proliferate during neurogenesis}

To determine directly if Rat 401-positive cells proliferate during neurogenesis we have used two independent methods: (1) FACS analysis of cells double-labeled with propidium iodide and Rat 401 and (2) double labeling with ${ }^{3} \mathrm{H}$-thymidine autoradiography and Rat 401 immunofluorescence.
600

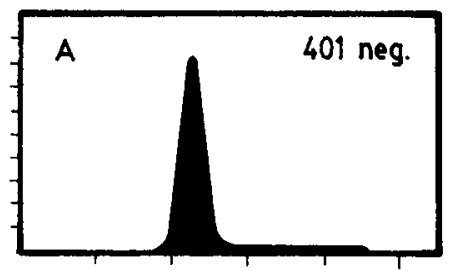

400
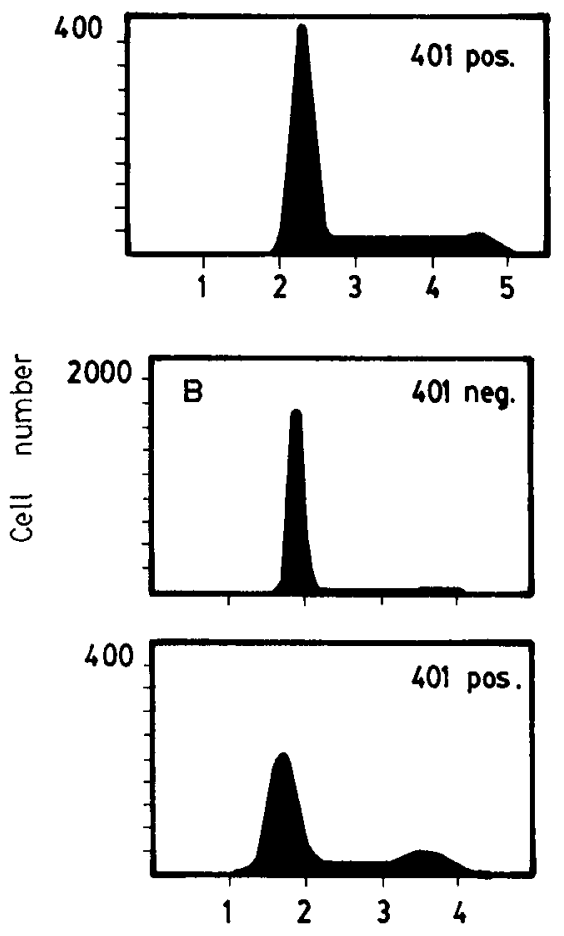

Relative DNA content

Figure 7. FACS analysis of propidium iodide and Rat 401 doublelabeled cells. Dissociated cell suspensions were stained with both propidium iodide and the monoclonal antibody Rat 401 , which was detected with a rhodamine-conjugated second antibody. The intensity of the 2 fluorescent labels was analyzed on a single-cell basis by passing the cell suspension through a FACS. The data show the intensity of propidium iodide fluorescence (relative DNA content) for Rat 401positive and -negative cells in the E15 spinal cord (A) and the E19 cerebrum $(B)$. The Rat 401-positive cells were clearly separated from negative cells by FACS analysis. The proportion of Rat 401-positive cells in $\mathrm{S}$ and $\mathrm{G} 2$ phases of the cell cycle (Table 1) was derived from this analysis.

Propidium iodide is a DNA intercalating fluorescent dye that allows cells to be analyzed and sorted in the FACS according to their DNA content. Dissociated cells were double-labeled with propidium iodide and Rat 401 . The cell cycle distribution of 401 -negative and -positive cells in E15 spinal cord and E19 cerebrum is shown in Figure 7 and throughout development in Table 1.

When embryos were labeled with ${ }^{3} \mathrm{H}$-thymidine and sacrificed $3 \mathrm{hr}$ later, the radiolabel directly marked actively proliferating cells. Dissociated CNS cells were labeled with both ${ }^{3} \mathrm{H}$-thymidine and Rat 401 . This double-labeling procedure gives an independent estimate of the proportion of 401-positive cells in S phase (Table 2 ). The values obtained with ${ }^{3} \mathrm{H}$-thymidine labeling are in close agreement with the percentage of cells in S and G2 phases of the cell cycle derived from flow cytometry.

These experiments show that with 2 independent methods 


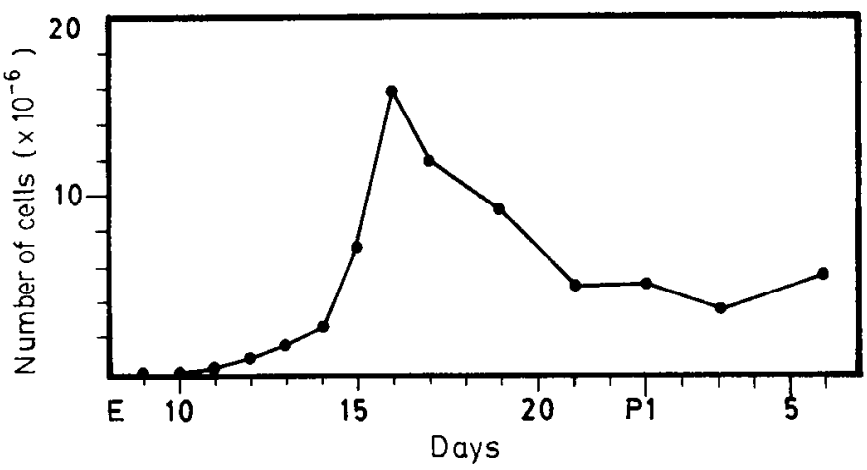

Figure 8. Number of Rat 401-positive cells during cerebral development. The number of Rat 401-positive cells was calculated from the total number of cells present on each day of cerebral development (Fig. 4) and the proportion of Rat 401-positive cells (Fig. 7). The number of Rat 401-positive cells increases to maximum on E16 and then declines during the period of neurogenesis.

Rat 401-positive cells are actively proliferating in the spinal cord and cerebrum through the period of neurogenesis.

\section{Absolute numbers of Rat 401-positive cells}

As wc know the total number of cells in different brain regions at different times of development, the proportion of Rat 401 positive cells shown in Figure 6 can be converted into absolute numbers of cells (Figs. 8, 9).

In the cerebrum the total number of Rat 401 cells reaches a maximum at E16 and then declines to a plateau on E21. The numbers of Rat 401 cells and the known cycle time for rat cerebral cortex neuroepithelial cells (Waechter and Jaensch, 1972) suggest that Rat 401 cells are present in sufficient numbers to generate the total numbers of cells in the cerebrum. On E16 there are $1.5 \times 10^{7}$ cells in the cerebrum; $88 \%$ are Rat 401 positive. On E17 there are $2.4 \times 10^{7}$ cells in the cerebrum; the increase of $0.9 \times 10^{7}$ cells can clearly be generated by the Rat 401-positive cells present on E16. These figures show that there are sufficient Rat 401-positive cells to account for a major portion of the total increase in cell number during neurogenesis in the cerebrum.

In the spinal cord it is possible to directly compare the number
Table 2. Proportion of replicating cells derived from thymidine radiolabeling

\begin{tabular}{llll}
$\begin{array}{l}\text { A. Percentage of total cells } \\
\text { labeled }\end{array}$ & B. Percentage rat 401 -positive \\
cells labeled & \\
\hline E12 & 66.9 & & 67.3 \\
E17 & 14.3 & Cerebrum & 28.3 \\
& & Spinal cord & 18.2 \\
\hline
\end{tabular}

of neurons born and the number of Rat 401-positive cells present on each day of neurogenesis. Because neurons do not divide, a stem cell must exist for every neuron. If Rat 401 labels all neuronal stem cells, then the absolute number of Rat 401-positive cells should equal or exceed the number of neurons born on each day of neurogenesis. The percentage of neurons born on different days in the development of the rat spinal cord has been measured by microscopic inspection of sections from the spinal cord of 6-week-old rats injected with ${ }^{3} \mathrm{H}$-thymidine on E11-E16 (Nornes and Das, 1974). We have measured the total number of cells in the spinal cord from E10 to postnatal day 9 (Fig. 4). As cell numbers rise to $9 \times 10^{6}$ on E16 and then remain constant until after birth, the number of neurons in the spinal cord cannot exceed $9 \times 10^{6}$. Using the data of Nornes and Das (1974) and our figure for the total number of cells in the spinal cord, at birth, we have calculated the numbers of neurons born on each day of spinal cord development (Fig. 9, open circles).

Although the relative number of Rat 401 cells declines from $\mathrm{E} 12$, the total number of positive cells continues to increase to a maximum on E15 and then declines (Fig. 9, closed circles). The number of Rat 401-positive cells present on each day and the number of neurons born on that day are in close agreement. It is clear from these data that in the spinal cord there are sufficient Rat 401 cells present to account for the generation of the majority of neurons.

\section{Discussion}

Identification of neuronal precursor cells

We have developed dissociation methods that allow quantitative recovery of dissociated cells from the embryonic vertebrate

Table 1. Distribution of cells in different phases of the cell cycle derived from flow cytometry

\begin{tabular}{|c|c|c|c|c|c|}
\hline \multirow[b]{2}{*}{ Age } & \multirow[b]{2}{*}{ Brain region } & \multirow{2}{*}{$\begin{array}{l}\text { Positive or } \\
\text { negative for } \\
\text { Rat } 401\end{array}$} & \multicolumn{3}{|c|}{ Cell cycle phase } \\
\hline & & & $\mathrm{G} 1+\mathrm{G} 0$ & $S$ & G2 \\
\hline \multirow[t]{2}{*}{$\mathrm{E} 12$} & Whole & - & $36.9 \pm 4.3$ & $60.7 \pm 4.5$ & $2.2 \pm 0.4$ \\
\hline & & + & $31.8 \pm 0.2$ & $65.0 \pm 0.6$ & $3.5 \pm 0.9$ \\
\hline \multirow[t]{2}{*}{ E15 } & Whole & - & $84.7 \pm 4.2$ & $10.9 \pm 0.5$ & $3.0 \pm 1.9$ \\
\hline & & + & $66.4 \pm 0.5$ & $25.7 \pm 1.5$ & $7.8 \pm 1.7$ \\
\hline \multirow[t]{4}{*}{ E16 } & Cerebrum & - & $84.5 \pm 3.6$ & $12.4 \pm 0.7$ & $3.1 \pm 0.9$ \\
\hline & & + & $70.4 \pm 0.7$ & $18.0 \pm 0.9$ & $11.6 \pm 2.7$ \\
\hline & Spinal cord & - & $91.3 \pm 0.3$ & $4.9 \pm 1.8$ & $3.7 \pm 2.6$ \\
\hline & & + & $71.1 \pm 0.6$ & $10.6 \pm 0.7$ & $16.5 \pm 0.8$ \\
\hline \multirow[t]{4}{*}{ E19 } & Cerebrum & - & $89.2 \pm 0.9$ & $6.6 \pm 1.6$ & $4.2 \pm 0.8$ \\
\hline & & + & $66.4 \pm 0.5$ & $16.8 \pm 0.3$ & $16.5 \pm 0.4$ \\
\hline & Spinal cord & - & $93.9 \pm 0.2$ & $4.0 \pm 3.8$ & $2.1 \pm 1.9$ \\
\hline & & + & $80.7 \pm 0.7$ & $11.8 \pm 0.4$ & $7.5 \pm 0.4$ \\
\hline
\end{tabular}




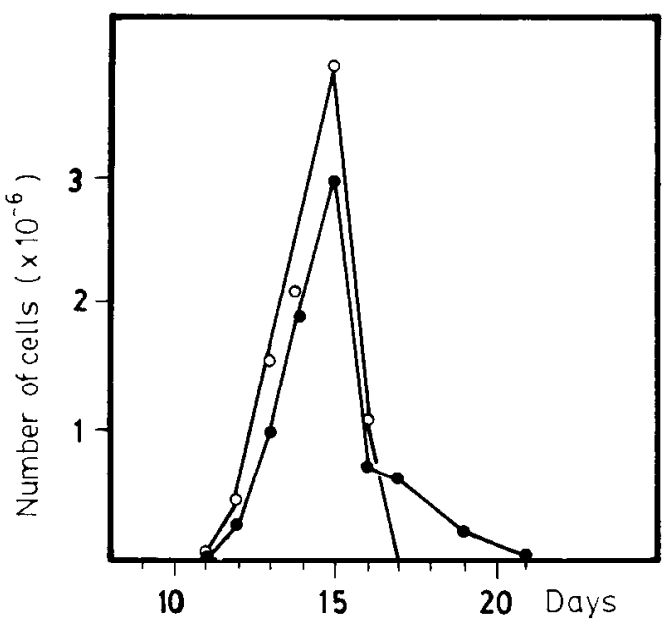

Figure 9. Number of Rat 401-positive cells during spinal cord development. The numbers of Rat 401-positive cells in the spinal cord (๑) was calculated from the proportion of stained cells (Fig. 7) and the total number of cells in the spinal cord (Fig. 4). The numbers of neurons which go through their last mitosis on different embryonic days $(O)$ was estimated from the proportion of neurons born on different days (Nornes and Das, 1974) and the total number of cells in the spinal cord after neurogenesis (Fig. 4).

nervous system. This cell preparation was then used in conjunction with immunohistochemistry and methods of identifying proliferating cells. The goal of these studies was to define antigenic markers expressed in neuroepithelial precursor cells. The monoclonal antibody Rat 401 was chosen on the basis of the cellular distribution of antigen in the E15 spinal cord as a candidate for a precursor cell marker.

The cells recognized by monoclonal antibody Rat 401 have properties expected of neuronal precursor cells:

1. Almost all the cells of the CNS are Rat 401-positive before neurons differentiate.

2. The proportion of Rat 401-positive cells falls during the period of neurogenesis.

3. During neurogenesis, Rat 401-positive cells proliferate.

4. The total number of positive cells is large enough to account for the generation of neurons.

5. During gliogenesis, less than $0.1 \%$ of the cells are Rat 401 positive, even though the number of glial cells exceeds the number of neurons.

While these data suggest that neuronal precursor cells express the antigen recognized by Rat 401 , it is also clear that after E12 a population of Rat 401-negative proliferating cells exists in the neuroepithelium. There are 2 possible explanations for this negative class. Neuronal precursor cells may cease to express Rat 401 prior to their final division before becoming postmitotic or a population of Rat 401-positive cells may cease to express the Rat 401 antigen and continue to proliferate through several cell cycles. As neuronal cell culture methods do not allow the precursor cell to divide (Banker and Cowan, 1979), a direct resolution of this question using primary cell culture methods is not possible at present. Rat 401 staining of primary cultures of the cerebral cortex in double-label experiments with anti-neurofilament antibodies shows that there is a transient co-expression of the Rat 401 antigen and neurofilaments in differentiating neurons (N. Valtz, K.F., R.M.). We have also generated immortal cell lines expressing the Rat 401 antigen that differentiate in culture, giving progeny with either neuronal or glial properties (K.F., P.-J. Jat, D. Levy, R.M., unpublished observations), supporting the conclusion that Rat 401 marks neuronal precursor cells.

\section{Control of cell number}

Our results are consistent with earlier experiments (see Jacobson, 1978) showing that there are 2 distinct periods of cell proliferation in the nervous system. The first occurs embryonically and correlates with neurogenesis, and the second occurs postnatally and correlates with gliogenesis. The separation between the neurogenic and gliogenic proliferative phases is particularly clear in the measurements of cell number in the spinal cord, where there is no change in cell number between the end of neurogenesis on E15 and birth. Studies on the chick spinal cord have suggested that neurons are produced in greater numbers than are found in the adult and that neuronal death may play an important role in neural development (Levi-Montalcini, 1950; Hamburger, 1975; Landmesser and Morris, 1975; Oppenheim et al., 1982). We show that during the neurogenic phase cell numbers increase 1000 -fold from $10^{5}$ cells at E10 to $10^{8}$ cells at E21. Although we know that there are mechanisms which strictly regulate cell number in the embryo, it is clearly clinically important to determine if the proliferation of neuroepithelial precursors transplanted to the adult brain is also tightly regulated. This issue is particularly important with the potential use of transplantation of embryonic CNS tissue to treat neural degenerative disease in man.

\section{Rat 401 antigen as a marker of a multipotential neuroepithelial precursors}

In this paper we have presented evidence consistent with the hypothesis that Rat 401 -positive proliferating cells are neuronal precursors. Are glial cells also derived from Rat 401-positive precursors? Rat 401 expression in primary tissue culture from E15 spinal cord and cerebrum shows that the antigen can be coexpressed with either glial fibrillary acidic protein (GFAP) or neurofilaments. GFAP is an intermediate filament protein that is found only in astrocytes in the adult brain (Antanitus et al., 1975). Rat 401 does not recognize glial cells in the adult rat brain (Hockfield and McKay, 1985). Coexpression of Rat 401 antigen and GFAP in cultured primary cells suggests that the antigen-positive cells can give rise to glial cells.

In another set of experiments, Rat 401-positive cell lines have been established from the postnatal cerebellum using the temperature-sensitive form of SV40 T antigen as the immortalizing oncogene (K.F., P.S. Jat, N. Valtz, D. Levy and R. M., unpublished observation). These clonal cell lines can be induced to adopt either neuronal or glial fates. As these cell lines are clonal, we conclude that both neurons and astrocytes can be derived from the same multipotential Rat 401-positive precursor cells.

Another interesting question is whether the oligodendroglial cells are derived from the same multipotential precursor cells. A2B5 has been shown to recognize a progenitor cell for oligodendrocytes and type 2 astrocytes in the optic nerve (Raff et al., 1985). In the cerebellum A2B5 is expressed on neurons (Schnitzer and Schachner, 1982) and is not an exclusive marker of oligodendroglial precursors. Galactocereberoside is expressed later in the development of oligodendrocytes than A2B5 and is restricted to oligodendrocytes in primary CNS cultures (Raff et al., 1978, 1979). A monoclonal anti-Gal $\mathrm{C}$ antibody binds to a surface antigen on a proportion of immortalized cerebellar pre- 
cursor cells (K.F., P. S. Jat, N. Valtz, D. Levy, R.M.), showing that these cells can activate biochemical pathways that are restrictcd to the oligodendrocytic lineage and suggesting that a single precursor cell can give rise to the 3 major cell types of the adult brain-neurons, astrocytes and oligodendrocytes.

\section{Are radial glial cells morphologically modified neuroepithelial precursor cells?}

One of the earliest cellular morphologies to differentiate in the CNS is the radial glial cell. Anatomical and immunohistochemical data suggest that radial glial cells play 2 roles in the development of the brain. First, they appear to provide the structural connection between the site where neurons are born and their peripheral location in the adult (Rakic, 1972, 1974). Second, there is evidence that radial cells are precursors to astrocytes (Schmechel and Rakic, 1979; Levitt et al., 1981). We have reported detailed anatomical evidence at the light and electron microscope levels which shows that the Rat 401 antigen is expressed in radial glial cells (Hockfield and McKay, 1985). The data presented here show that this antigenic marker is also present in neuronal stem cells. An interpretation consistent with these data is that radial glial cells are multipotential neuroepithelial precursor cells with a modified morphology.

\section{References}

Angevine, J. B. (1970) Critical cellular events in the shaping of neural centers. In The Neurosciences: Second Study Program, F. O. Schmitt, ed., pp. 62-72, Rockefeller University Press, New York.

Antanitus, D. S., B. H. Choi, and L. W. Lapham (1975) Immunofluorescence staining of astrocytes in vitro using antiserum to glial fibrillary acidic protein. Brain Res. 89: 363-367.

Banker, G. A., and W. M. Cowan (1979) Further observations on hippocampal neurons in dispersed cell culture. J. Comp. Neurol. 187: $469-494$.

Berry, M., and A. W. Rogers (1965) The migration of neuroblasts in the developing cerebral cortex. J. Anat. 99: 691-709.

Berry, M., A. W. Rogers, and J. T. Eayrs (1964) Pattern of cell migration during cortical histogenesis. Nature 203: 591-593.

Bignami, A., T. Raju, and D. Dahl (1982) Localization of vimentin, the nonspecific intermediate filament protein, in embryonal glia and in early differentiating neurons. Dev. Biol. 91: 286-295.

Bravo, R, and H. Bravo-McDonald (1985) Changes in the nuclear distribution of cyclin in (PCNA) but not its synthesis depend on DNA replication. EMBO J. 4: 655-661.

Christie, G. A. (1965) Developmental stages in somite and postsomite rat embryos, based on external appearance, and including some features of the macroscopic development of the oral cavity. J. Morphol. 114: 263-286.

Chung, S.-H., and J. Cooke (1975) Polarity of structure and of ordered nerve connections in the developing amphibian brain. Nature 258 : 126-132.

Cowan, W. M. (1979) Selection and control in neurogenesis. In The Neurosciences: Fourth Study Program, F. O. Schmitt and F. G. Worden, eds., pp. 59-79, MIT Press, Cambridge, MA.

Fedoroff, S. (1985) Macroglial cell lineages. In Molecular Bases of Neuronal Development, G. M. Edelman, W. E. Gall, and W. M. Cowan, eds., pp. 91-119, Wiley, New York.

Glucksmann, A. (1951) Cell deaths in normal vertebrate ontogeny. Biol. Rev. 26: 59-86.

Gray, J. W., and P. N. Dean (1980) Display and analysis of flow cytometric data. Annu. Rev. Biophys. Bioeng. 9: 509-539.

Hamburger, V. (1975) Cell death in the development of the lateral motor column of the chick embryo. J. Comp. Neurol. 160: 535-546.
Hockfield, S., and McKay, R. (1985) Identification of the major cell classes in the early mammalian neural tube. J. Neurosci. 12: 33103328.

Jacobson, M. (1978) Developmental Neurobiology, Plenum Press, New York.

Labarca, C., and K. Paigen (1980) A simple, rapid and sensitive DNA assay procedure. Anal. Biochem. 102: 344-352.

Landmesser, L., and D. G. Morris (1975) The development of functional innervation in the hind limb of the chick embryo. J. Physiol. (Lond.) 249: 301-326.

Levi-Montalcini, R. (1950) The origin and development of the visceral system in the spinal cord of the chick embryo. J. Morphol. 86: 253278.

Levine, J. M., L. Beasley, and W. B. Stallcup (1984) The D1.1 antigen: A cell surface marker for the germinal cells of the central nervous system. J. Neurosci. 4: 820-831.

Levitt, P., M. L. Cooper, and P. Rakic (1981) Coexistence of neuronal and glial precursor cells in the cerebral ventricular zone of the fetal monkey: An ultrastructural immunoperoxidase study. J. Neurosci. $I$ : 27-39.

Mangold, O. (1929) Experimente zum analyse der determination und induktion der medullarplatte. Wilhelm Roux Arch. 117: 586-696.

Nornes, H. O., and G. D. Das (1974) Temporal pattern of neurogenesis in spinal cord of rat. I. An autoradiographic study-Time and sites of origin and migration and settling patterns of neuroblasts. Brain Res. 73: 121-138.

Oppenheim, R. W., J. L. Maderdrut, and D. J. Wells (1982) Cell death of motor neurons in the chick embryo spinal cord. J. Comp. Neurol. 210: 174-189.

Prestige, M. C. (1970) Differentiation, degeneration and the role of the periphery: Quantitative considerations. In The Neurosciences: Second Study Program, F. O. Schmitt, ed., pp. 73-82, Rockefeller University Press, New York.

Raff, M. C., R. Mirsky, K. L. Fields, R. P. Lisak, S. H. Dorfman, D. H. Silberberg, N. A. Gregson, S. Liebowitz, and M. C. Kennedy (1978) Galactocereberoside is a specific cell surface marker for oligodendrocytes in culture. Nature 274:813-816.

Raff, M. C., K. L. Fields, S.-I. Hakamori, R. M. Mirsky, R. Pruss, and J. Winter (1979) Cell type specific markers for distinguishing and studying ncurons and the major classes of glial cells in culture. Brain Res. 174: 283-308

Raff, M. C., E. R. Abney, and J. Fok-Seang (1985) Reconstitution of a developmental clock in vitro: A critical role for astrocytes in the timing of oligodendrocyte differentiation. Cell 42: 61-69.

Rakic, P. (1972) Mode of cell migration to the superficial layers of the monkey fetal cortex. J. Comp. Neurol. 145: 61-84.

Rakic, P. (1974) Neurons in Rhesus monkey visual cortex: Systematic relation between time of origin and eventual disposition. Science 183: $425-427$.

Santen, R. J., and B. W. Agranoff (1963) Studies on the estimation of DNA and RNA in rat brain. Biochim. Biophys. Acta 72: 251-262.

Sauer, M. E., and B. E. Walker (1959) Radioautographic study of interkinetic nuclear migration in the neural tube. Proc. Soc. Exp. Biol. Med. 101: 557-560.

Schmechel, D. E., and P. Rakic (1979) A golgi study of radial glial cells in developing monkey telencephalon: Morphogenesis and transformation into astrocytes. Anat. Embryol. 156:115-152.

Schnitzer, J., and M. Schachner (1982) Cell type specificity of a neural cell surface antigen recognized by the monoclonal antibody A2B5. Cell Tissue Res. 224: 625-636.

Sidman, R. L., I. L. Miale, and N. Feder (1959) Cell proliferation and migration in the primitive ependymal zone: An autoradiographic study of histogenesis in the nervous system. Exp. Neurol. 1: 322-333.

Tapscott, S. J., G. S. Bennett, Y. Toyama, F. Kleinbart, and H. Holtzer (1981) Intermediate filament proteins in the developing chick spinal cord. Dev. Biol. 86: 40-54.

Waechter, R. V., and B. Jaensch (1972) Generation times of the matrix cells during cmbryonic brain development: An autoradiographic study in rats. Brain Res. 46: 235-250. 